\title{
Comparative Analysis between Fuzzy and Traditional Analytical Hierarchy Process
}

\author{
Freselam Mulubrhan ${ }^{1, a}$, Ainul Akmar Mokhtar ${ }^{2}$ and Masdi Muhammad ${ }^{3}$ \\ 1,2,3 Mechanical Engineering Department, Universiti Teknologi PETRONAS Bandar Seri Iskandar, \\ 31750 Tronoh, Perak, Malaysia
}

\begin{abstract}
Analytic Hierarchy Process (AHP) is one of the techniques commonly used for prioritizing different alternatives, by using complex criteria. In real applications, conventional AHP assumes the expert judgment as it is exact and use crisp number leading to inconsideration of the uncertainty that came from linguistic variable. Fuzzy logic deals with situations which are vague or unwell defined and gives a quantify value. In this study a comparison is made between traditional AHP and fuzzy AHP by taking a case of selecting an effective oil refinery. The selection is conducted using system effectiveness as a criterion. The two approaches have been compared on the same hierarchy structure and criteria set and the result show that in both case dual drum scheme (DDS) has the highest priority but different value that is 0.51 and 0.36 for AHP and FAHP respectively which shows that if the expert opinion is certain AHP should be used if not FAHP should be preferred
\end{abstract}

\section{Introduction}

In order to excel in the competitive market, industries need to make a faultless decision. Even though it is difficult to make such decisions, it is possible to minimize it by taking into account all possible factors which contribute the biggest share. These factors can be quantitative or qualitative. Taking into account only quantitative factors like cost does not bring a convincing decision making analysis. Decision support system should be used to incorporate the non-financial factors into the decision making processes together with the financial factors. One of the known decision making tool is Multi-criterion decision making (MCDM). MCDM is used to make decision in situation which has many and contradictory criteria [1]. There are different methodologies for MCDM that are currently in use such as goal programming, grey relational analysis, dominance-based rough set approach, multiattribute global inference of quantity, analytic hierarchy process (AHP), outranking methods and multi-criteria utility theory. The choice of AHP amongst other MCDM techniques is because it offers a convenient way to quantify the qualitative attributes of the options presented, hence removing subjectivity in the result [2]. Professor T. L. Saaty developed AHP in 1970s. The method is used vastly in different applications due to its ability to make decisions by making a pair wise comparison of uncertain, qualitative and quantitative factors and also its ability to model expert opinion.

The conventional AHP is based on a hierarchical structure of goal, criterion and alternative. The criteria will be assessed by the goal and each alternative will be assessed by each criterion which will

${ }^{\text {a }}$ Corresponding author : frity $4 \mathrm{u} @$ yahoo.com 
give a final value by the determined weight coefficient [3]. This method uses the nine point scale developed by Saaty for evaluation of the goal with the criterion as well as the criterion with the alternative $[2,3]$. The decision making process relies on data about the alternatives. The data can be certain which is deterministic or it can be intangible or uncertain which can be represented by the fuzzy set theory and if the uncertain data are random then probability and statistics will be used. This diversity in type and quality of information about a decision problem calls for methods and techniques that can assist in analysing the data. However; the conventional method of Saaty's AHP has some deficiencies where the subjective descriptions of reviewers' decision are often corresponding to an exact value. As a result, the vague semantic descriptions are often ignored by the researchers.

In order to make the analysis results more reasonable, fuzzy set theory is used to deal with the problems of fuzziness. This method is called Fuzzy Analytic Hierarchy Process (FAHP) which combines the fuzzy theory and AHP [4].Fuzzy theory overthrows the two/dual value (i.e. yes or no) and the principle of excluded middle, so that its multi-value could be pressed close to reality. The earliest work integrating between fuzzy logic and AHP concepts appeared in the early 1980s, with several researchers working on the concepts and starting to determine fuzzy priorities of comparison ratios by using the geometric mean $[4,5,6]$. In the 1990s, studies in FAHP became more popular and several improvements on the methods were developed [7,8]. The concept of using triangular fuzzy numbers for pair wise comparison scale and the extent analysis methods for synthetic extents first introduced by Chang in 1996 [9]. Several research studies have proved the effectiveness of this method $[9,10]$. In this paper a comparison will be made between the two methods (AHP and FAHP), to highlight the effect of linguistic judgment on the decision.

\section{AHP and FAHP Methodology}

The FAHP technique is a highly developed analytical method from the AHP. Both methods follow a similar algorithm up to checking the consistency of the matrix. The difference comes in the 6th step. Step 6a; Priority calculations is conducted for traditional AHP while in Step 6b; extent analysis is conducted for FAHP. The method of AHP and FAHP is shown in the Figure 1.

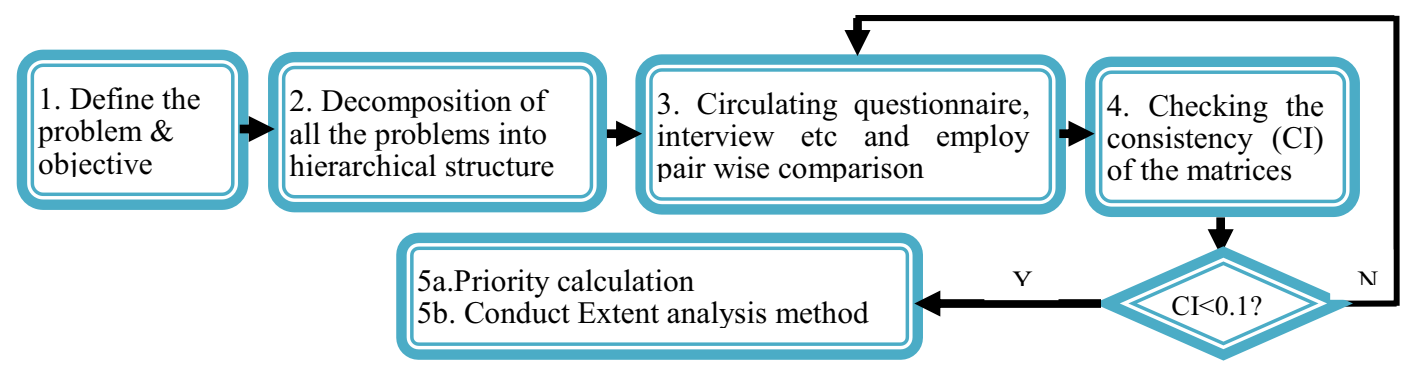

Figure 1. AHP and FAHP methodology

Any decision making process begins with the identification of the problem under investigation. There are different options with, pros and cons, which are helpful in solving the identified problems. Analyzing the pros and cons has to be the first step of these methodologies. The second step should be to decompose the entire problem into hierarchical structures which has three levels; the goal of the decision; the criteria; and the options. The decision maker expresses judgments in terms of pair wise comparisons on each level using verbal judgments which will be translated into numbers. In AHP this numbers have crisp value however, in FAHP this numbers are expressed in triangular fuzzy number. The membership function of a triangular fuzzy number lies in the interval of $[0,1], \&$ it is expressed as:

$$
\mu_{M}(x)=\{(x / m-l)-(l / m-l), \ldots \ldots \ldots \ldots x \in[l, m],(x / m-u)-(u / m-u), \ldots \ldots \ldots . . . x \in[m, u] .
$$

where $l \leq m \leq u$, $\mathrm{u}$ and $l$ are the upper and lower value of the modal $\mathrm{m}$ of thefuzzy triangular number which is denoted by $(\mathrm{l}, \mathrm{m}, \mathrm{u})$ respectively. If $\mathrm{l}=\mathrm{m}=\mathrm{u}$, it becomes the ordinary number (i.e. non- 
fuzzy, crisp). The support of $m$ is the $\operatorname{set}\left\{x \in \frac{R}{l}, x, u\right\}$ where $R$ is a real number and $\mu_{A}(x)$ is the membership function. There also involve an operation in a fuzzy matrix. The sum, subtraction, and multiplication of a two triangular fuzzy number is similar to crisp numbers the only different operation is on the inverse. The crisp value and the triangular fuzzy numbers (TFN) are shown in Table 1.

Table 1: Pair wise Comparison of AHP and FAHP [11]

\begin{tabular}{|c|c|c|c|c|c|}
\hline & Equal & Weakly & Essentially & Very strongly & Absolutely \\
\hline Crisp Value & 1 & 3 & 5 & 7 & 9 \\
\hline TFN & $(1,1,3)$ & $(5,7,9)$ & $(3,5,7)$ & $(5,7,9)$ & $(7,9,9)$ \\
\hline Inverse TFN & $(1 / 3,1,1)$ & $(1 / 5,1 / 3,1)$ & $(1 / 7,1 / 5,1 / 3)$ & $(1 / 9,1 / 7,1 / 5)$ & $(1 / 9,1 / 9,1 / 7)$ \\
\hline
\end{tabular}

The pair wise comparison in AHP is given by the expert opinion; this opinion could be or could not be consistent. In order for the results to be true, it is a must to check the consistency of these opinions [12]. AHP develops a consistency measure, by using consistency ratio that is calculated using the consistency index, CI and random index, RI. Eigenvalue $\lambda$ and eigenvector value are used to determine the consistency index. It shows weather the expert opinion is consistent or not.

$$
\mathrm{CI}=\frac{\lambda_{\max }-\mathrm{n}}{\mathrm{n}-1} \text {. }
$$

where $\lambda_{\max }$ is the maximum eigenvalue, and $\mathrm{n}$ is the dimension of the judgment matrix. RI is obtained by averaging CI of a randomly generated reciprocal matrix. The calculated consistency ration should be less than or equal to 0.1 , that means it is only acceptable if the inconsistency is below $10 \%$. In FAHP, the pair wise comparison matrix is given by triangular fuzzy number and these numbers need to be changed to crisp number to calculate the consistency ratio. For this defuzzification is needed. For further details on defuzzification method, refer to [11]. In AHP Once all pair-wise comparisons are conducted and are confirmed to be consistent, the judgments can then be synthesized to find out the priority ranking of each criterion and its attributes by using the eginvector and eginvalue. In FAHP extent analysis method is used to consider the extent of an object to be satisfied for the goal, that is, satisfied extent. In the method, the "extent" is quantified by using a fuzzy number. For further details on the method of priority calculation and extent analysis, refer to [2, 9] respectively.

\section{Result and Discussion}

The case of topping refinery was extracted from Okafor [13]. Okafor analyzed three types of topping refineries using AHP. These are Pre-flash Drum Scheme (PDS), Pre-fractionators Scheme (PS), and Dual Drum scheme (DDS). The pair wise comparison was made using four criteria; Reliability (R), Maintainability (M), Capacity (C) and Flexibility (F). These comparisons were given by a panel of experts, who are $\mathrm{PhD}$ researchers in a related research area. The result shows that DDS has the highest overall priority of 0.51 , while PDS and PS have 0.25 and 0.24 overall priorities, respectively. In this study the crisp pair wise comparisons given in original study were converted to a fuzzy number as shown in Table 2 and Table 3 and then, FAHP was conducted. The first analysis is made between each criterion. The value of fuzzy synthetic extent with respect to the $i^{\text {th }}$ object is, $\mathrm{S}_{\mathrm{I}}$, therefore for each criterion the extent value is represented by $\mathrm{S}_{\mathrm{R}}, \mathrm{S}_{\mathrm{M}}, \mathrm{S}_{\mathrm{C}}$, and $\mathrm{S}_{\mathrm{F}}$

$\mathrm{S}_{\mathrm{R}}=(7 ; 12 ; 18) *(1 / 42.83,1 / 28.283,1 / 18.26)=(0.163 ; 0.424 ; 0.986)$

$\mathrm{S}_{\mathrm{M}}=(7.25 ; 10.5 ; 11) *(1 / 42.83,1 / 28.283,1 / 18.26)=(0.169 ; 0.371 ; 0.602)$

$\mathrm{S}_{\mathrm{C}}=(2.417 ; 3.75 ; 4.5) *(1 / 42.83,1 / 28.283,1 / 18.26)=(0.056 ; 0.13 ; 0.246)$

$\mathrm{S}_{\mathrm{F}}=(1.593 ; 2.033 ; 2.833) *(1 / 42.83,1 / 28.283,1 / 18.26)=(0.037 ; 0.072 ; 0.155)$

Using these vectors a principle of comparison of fuzzy numbers is used to attain the weigh vales under each criterion. 
$\mathrm{V}\left(\mathrm{S}_{\mathrm{R}} \geq \mathrm{S}_{\mathrm{M}}\right)=1.07 ;\left(\mathrm{S}_{\mathrm{R}} \geq \mathrm{S}_{C}\right)=1.46 ;\left(\mathrm{S}_{\mathrm{R}} \geq \mathrm{S}_{\mathrm{F}}\right)=1.59 ;\left(\mathrm{S}_{\mathrm{M}} \geq \mathrm{S}_{\mathrm{R}}\right)=0.09 ;\left(\mathrm{S}_{\mathrm{M}} \geq \mathrm{SC}_{\mathrm{C}}\right)=0.027 ;\left(\mathrm{S}_{\mathrm{M}} \geq \mathrm{S}_{\mathrm{F}}\right)=2.13 ;$ $\mathrm{V}\left(\mathrm{S}_{\mathrm{C}} \geq \mathrm{S}_{\mathrm{R}}\right)=0.22 ;\left(\mathrm{S}_{\mathrm{C}} \geq \mathrm{S}_{\mathrm{M}}\right)=0.24 ;\left(\mathrm{S}_{\mathrm{C}} \geq \mathrm{S}_{\mathrm{F}}\right)=1.41 ;\left(\mathrm{S}_{\mathrm{F}} \geq \mathrm{S}_{\mathrm{R}}\right)=-0.024 ;\left(\mathrm{S}_{\mathrm{F}} \geq \mathrm{S}_{\mathrm{M}}\right)=-0.049,\left(\mathrm{~S}_{\mathrm{F}} \geq \mathrm{S}_{\mathrm{C}}\right)=0.619$

Table 2: Expert Opinion on the criterion

\begin{tabular}{|c|c|c|c|c|}
\hline & $\mathrm{R}$ & $\mathrm{M}$ & $\mathrm{C}$ & $\mathrm{F}$ \\
\hline $\mathrm{R}$ & $(1,1,1)$ & $(1,2,4)$ & $(2,4,6)$ & $(3,5,7)$ \\
\hline $\mathrm{M}$ & $(1 / 4,1 / 2,1)$ & $(1,1,1)$ & $(1,2,4)$ & $(5,7,9)$ \\
\hline $\mathrm{C}$ & $(1 / 6,1 / 4,1 / 2)$ & $(1 / 4,1 / 2,1)$ & $(1,1,1)$ & $(1,2,4)$ \\
\hline $\mathrm{F}$ & $(1 / 7,1 / 5,1 / 3)$ & $(1 / 5,1 / 3,1)$ & $(1 / 4,1 / 2,1)$ & $(1,1,1)$ \\
\hline
\end{tabular}

Thus the weight vector from table 2 is found to be $W^{\prime}=(1,0.892,0.222,0)^{\mathrm{T}}$, through normalization, the weight vectors with respect to the decision criteria is found to be $\mathrm{W}=(0.473,0.422$, $0.105,0)$.

Next each topping refineries PS, DDS, and PDS are compared under each of the criteria separately. This is shown in the Tables 3 below. The consistency ratio for each matrix is calculated and it is found that all the values are less than 0.1 which shows the opinions given are consistent.

Table 3: Expert opinion on the alternatives

(a)

\begin{tabular}{|c|c|c|c|c|}
\hline R & PS & DDS & PDS & W(R) \\
\hline PS & $(1,1,1)$ & $(1 / 5,1 / 3,1)$ & $(1,3,5)$ & 0.375 \\
\hline DDS & $(1,3,5)$ & $(1,1,1)$ & $(3,5,7)$ & 0.573 \\
\hline PDS & $(1 / 5,1 / 3,1)$ & $(1 / 7,1 / 5,1 / 3)$ & $(1,1,1)$ & 0.051 \\
\hline
\end{tabular}

(c)

\begin{tabular}{|c|c|c|c|c|}
\hline C & PS & DDS & PDS & W(C) \\
\hline PS & $(1,1,1)$ & $(1 / 7,1 / 5,1 / 3)$ & $(1,3,5)$ & 0.2 \\
\hline DDS & $(3,5,7)$ & $(1,1,1)$ & $(5,7,9)$ & 0.8 \\
\hline PDS & $(1 / 5,1 / 3,1)$ & $(1 / 9,1 / 7,1 / 5)$ & $(1,1,1)$ & 0 \\
\hline
\end{tabular}

Performing extent analysis method uses intersection operations during evaluation values found from the comparison. The intersection of two fuzzy values can be found zero which shows that, the criterion under investigation has no significance. Flexibility has zero value during comparison of each criterion with the goal when using FAHP; however it has the value of 0.086 using AHP. The difference between FAHP and AHP comparison is that, in FAHP if a criterion has a very less important than the other competitors then it has no significance, and the value will be zero, which gives a very good implication to the decision maker that having this criterion is not significant in the decision making. The final process is to find the total weight by adding the weights for each alternative and multiplying it by the value of the weight of the criteria. This yields a final score of 0.35 for PS, 0.36 for DDS and 0.30 for PDS as shown in figure 2 below.

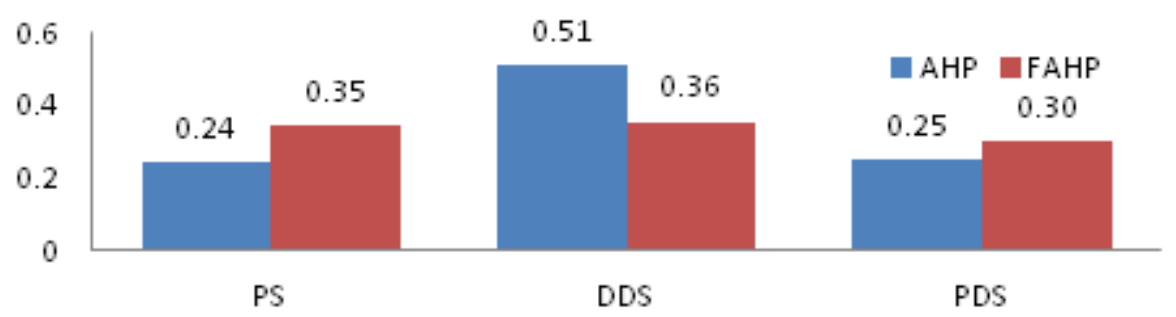

Figure 2. Final priority weight of each topping refinery option

Using FAHP still the first priority is to use DDS which has a lesser value than the priority found using AHP analysis; however the second preference is PS with the value of 0.35 however the second preference was PDS when using AHP with a priority of 0.25 . 


\section{Conclusion}

In this study, the comparative analysis of AHP and FAHP is presented for the multi-criteria topping refineries. Using AHP, Okafor found that DDS has the highest priority that is 0.51 , using FAHP even though still DDS has the highest priority but the value is 0.36 . The difference occurs on the second preference which is found to be PDS with a value of 0.25 using AHP and PS with a value of 0.35 using FAHP. When using AHP method, it is important to make sure that the opinions given by the experts are full of proficiency, harmony and carefulness. If these cases are fulfilled then AHP can be an effective problem solving methodology. However AHP method used nearly a crisp decision application which doesn't take into account the uncertainty of one's judgement. By its nature linguistic values are not consistent which needs to take the fuzziness into account in order to decrease the risk of making wrong decisions. The main focus here is that if the information/evaluations are certain, classical method should be preferred; if the information/evaluations are not certain, fuzzy method should be preferred. In addition FAHP approach provides to eliminate the unnecessary criterion if all of the decision makers assign "absolutely not important" value when compared with the other criteria and expresses the more important criteria. This helps the decision maker to focus on the highly important criterion.

\section{References}

1. $\mathrm{Xu}, \mathrm{L}$. and J.Yang, Introduction to Multi-Criteria Decision Making and the Evidential Reasoning Approach, Working Paper No. 0106, (2001)

2. N. Tiwari, Using the Analytic Hierarchy Process (AHP) to identify Performance Scenarios for Enterprise Application, (2006)

3. H. Zhao, S. Xu, J. He, AHP, A new simple method for the decision-making, Science Press, pp.61-87, (1986)

4. Yu, E. L., The Study of Fuzzifying Multiplicative Analytic Hierarchy Process, Master Dissertation, Tunghai University (1995).

5. G.deGraan and F.Lootsma, Multi-criteria decision analysis with fuzzy pair wise comparisons, Fuzzy sets and systems 29(2): 133-143. (1989).

6. J.J. Buckley, Fuzzy hierarchical analysis, Fuzzy sets and Systems 17(3): 233-247,(1985).

7. V. Laarhoven, and W.Pedrycz, A fuzzy extension of Saaty's priority theory, Fuzzy set and systems 11 (13):199-227,(1983).

8. D. Hepu, Multi criteria analysis with fuzzy pair wise comparison, International Journal of Approximate Reasoning 21(3): 215-231:(1999)

9. D. Y. Chang, Applications of the extent analysis method on fuzzy AHP, European Journal of Operation Research 95 (3): 649-655:(1996)

10. T. Aysegul, A Fuzzy AHP approach for selecting a global supplier in pharmaceutical industry, African Journal of Business Management 6(14), pp. 5073-5084, (2012).

11. A. P. Chansaad et.al, A Fuzzy Time-Driven Activity-Based Costing Model in an Uncertain Manufacturing Environment, Proceedings of the Asia Pacific Industrial Engineering \& Management Systems Conference (2012).

12. B. Başaran, A Critique on the Consistency Ratios of Some Selected Articles Regarding Fuzzy AHP and Sustainability, 3rd Intl. Symposium on Sustainable Development, (2012).

13. O.P. Okafor, Application of Analytic Hierarchy Process (AHP) In The Selection Of An Effective Refinery For Life Cycle Cost Analysis, International Journal of Engineering Research \& Technology (IJERT) 2(1), (2013). 